\title{
REFLEXÕES SOBRE EVASÃO ESCOLAR: uma problemática na educação brasileira
}

\author{
Jucenilton Alves dos Santos
}

\section{Resumo}

Este artigo tem como objetivo evidenciar a relação do alto índice de evasão escolar, distorção idade/série em sala de aula com a não efetivação do planejamento. Discute sobre como o planejamento pode contribuir para a aproximação do conhecimento científico e o conhecimento nascido no ambiente do cotidiano, ratificado pelo senso comum. Ambos devem estar interligados na construção e emancipação da cidadania dos educandos. A consciência da necessidade dos saberes sistematizados cientificamente, saber formal, ocorre quando esses têm uma valorização no ambiente extraescolar, saber informal, no cotidiano dos estudantes. A função social da escola é considerar os aspectos culturais e valorativos e realçar o saber popular articulado ao conteúdo escolar e esse é um questionamento constante.

Palavras-chave: planejamento; educação; evasão escolar.

\section{REFLECTIONS ON SCHOOL EVASION: a problematic in brazilian education}

\begin{abstract}
This article aims to highlight the relationship between the high school dropout rate, age / grade distortion in the classroom and the failure to carry out the planning. Discusses how planning can contribute to the approximation of scientific knowledge and knowledge born in the everyday environment, ratified by common sense. Both must be interconnected in the construction and emancipation of the students' citizenship. The awareness of the need for scientifically systematized knowledge, formal knowledge, occurs when they have an appreciation in the extra-school environment, informal knowledge, in the students' daily lives. The social function of the school is to consider cultural and evaluative aspects and to highlight popular knowledge linked to school content and this is a constant questioning.
\end{abstract}

Keywords: planning; education; school evasion.

\section{REFLEXIONES SOBRE EVASIÓN ESCOLAR: una problemática en la educación brasileña}

\begin{abstract}
Resumen
Este artículo tiene como objetivo resaltar la relación entre la tasa de abandono escolar, la distorsión de edad / grado en el aula y la imposibilidad de llevar a cabo la planificación. Discute cómo la planificación puede contribuir a la aproximación del conocimiento científico y el conocimiento nacido en el entorno cotidiano, ratificado por el sentido común. Ambos deben estar interconectados en la construcción y emancipación de la ciudadanía de los estudiantes. La conciencia de la necesidad de conocimiento científicamente sistematizado, conocimiento formal, ocurre cuando aprecian el ambiente extraescolar, el conocimiento informal, en la vida diaria de los estudiantes. La función social de la escuela es considerar aspectos culturales y evaluativos y resaltar el conocimiento popular vinculado al contenido escolar y esto es un cuestionamiento constante.
\end{abstract}

Palabras clave: planificación; la educación; evasión escolar. 


\section{INICIANDO O DIÁLOGO}

O sistema educacional do Brasil ainda encontra-se diante de muitos desafios, dentre os quais se destaca a evasão escolar, temática que está sempre presente no âmbito educacional e tem ganhado destaque nas discussões atuais, pois ainda se apresenta como um grande problema a ser encarado pelas redes e sistemas de ensino, pela sociedade e pela União. A evasão escolar não é um problema limitado apenas a algumas unidades escolares, mas é um problema brasileiro que vem ocupando importante papel nas discussões educacionais no cenário nacional, assim como a temática do analfabetismo e da não valorização dos professores expressa na baixa remuneração e nas escassas condições de trabalho. Por conta disto, educadores brasileiros vêm preocupando-se cada dia mais com as crianças que chegam à escola e, entretanto, nela não permanecem (Queiroz, 2011).

A evasão nas escolas, merece dessa forma uma certa atenção especial, pois não se trata de um problema restrito a algumas escolas, mas sim, um problema de âmbito nacional, que atinge principalmente as classes mais desfavorecidas da sociedade. Segundo Mello,

deve-se reconhecer, por exemplo, que o País conseguiu desenvolver centros de excelência no ensino superior e alcançou um padrão bastante avançado de investigação em áreas científicas e tecnológicas. No entanto, a convivência mesma desses avanços com a situação de penúria da escola obrigatória de base mostra o descompasso do sistema com as novas demandas econômicas e sociais, que supõem um salto educacional da sociedade como um todo (MELLO, 1991, p. 106).

Evasão escolar no Brasil é um problema de longas datas, que vem dando novos rumos à educação até hoje. Essa situação ainda existe no Ensino Fundamental (doravante EF), mas o que chama atenção mesmo é o número de alunos que abandonam o Ensino Médio (doravante EM), parando definitivamente ou por um tempo, os seus estudos. "O conceito de evasão vai além do emaranhado de palavras que juntas o formam, antes, perpassa por questões cognitivas, psicoemocionais, socioculturais, socioeconômicas, institucionais e atitudinais (BRASIL, 2006)".

Essa situação pode ser ligada a muitos obstáculos, considerados, muitas vezes, intransponíveis para milhares de jovens e adolescentes que se afastam da escola e não concluem a educação básica, ao menos. Dentre tais índices, destaca-se: a necessidade de trabalhar para ajudar a família; escola distante de casa; não ter um adulto que leve até a unidade escolar; falta de interesse e doenças; falta de transporte escolar; a necessidade de sustentarem-se; o ingresso na criminalidade e na violência; dentre outros.

Não se sabe ao certo, no Brasil, a quem culpar de forma mais específica pela evasão escolar, já que nesse contexto surgem variados responsáveis envolvidos de forma direta e indireta. A evasão afeta não somente uma região do Brasil, mas todo o território nacional. Não se sabe até quando se tem que conviver com esse quadro tão absurdo pelo qual está passando a educação em todo território brasileiro. Infelizmente, o sistema educacional brasileiro não tem sido pleno no que concerne ao alcance de todos os cidadãos e também no que se refere à conclusão de todos os níveis de escolaridade. 


\section{PLANEJAMENTO: O CAMINHO PARA UM EFETIVO SUCESSO ESCOLAR}

O processo de planejar é uma constante na vida do ser humano, pois mesmo que não haja uma organização escrita do fazer, o planejamento está presente no dia a dia do homem quando organiza seu dia de trabalho, os lugares que visitará, o que colocar na lista de compra, dentre outros.

É evidente que é o planejamento que dá aos professores a dimensão da importância de suas aulas e os objetivos a que ela se destina, assim como o tipo de cidadão que pretende formar. Desta maneira, pensar que a experiência de anos de docência é suficiente para a realização de um bom trabalho é um dos principais motivos que levam um professor a não obter sucesso em suas aulas. Entendemos então, que planejar é essencial para uma vida em sociedade, por viabilizar uma organização centrada em objetivos e prioridades, visualizando as metas e os meios para alcançálos.

Padilha (2001) traz para nós um conceito bastante claro de planejar:

O ato de planejar é sempre processo de reflexão, de tomada de decisão sobre a ação; processo de previsão de necessidades e racionalização de emprego de meios (materiais) e recursos (humanos) disponíveis, visando à concretização de objetivos, em prazos determinados e etapas definidas, a partir dos resultados das avaliações (PADILHA, 2001, p.30).

Vários são os tipos de planejamentos a depender da organização, mas a escola por muito tempo apropriou-se de um tipo de planejamento que naquele período talvez, servia a contento, o planejamento tradicional, muito utilizado em empresas. Vale salientar que planejamento é completamente diferente de plano.

Ainda de acordo com Padilha (2001), o plano é a "apresentação sistematizada e justificada das decisões tomadas relativas à ação a realizar." Plano tem a conotação de produto do planejamento. Para que haja plano é preciso que aconteça discussão (ou seja, planejamento) sobre fins e objetivos, culminando com a definição dos mesmos. Ele é, entretanto, um guia com a função de orientar a prática. O plano é, portanto, a formalização do processo de planejar.

Este fora utilizado por muito tempo, mas, não mais supre as necessidades desta escola democrática, por não atender ao caráter político que tem a função de possibilitar a participação de todos na busca de alcançar os objetivos estabelecidos, após exigentes processos de observação e análises de resultados. Sendo determinista não faz as leituras necessárias às realidades que se apresentam no momento do levantamento dos problemas. Além disso, tem como fundamento a imposição, sem, no entanto ater-se às diversas opiniões que circulam naquele espaço, não levando em conta os indivíduos que irão executá-los.

Mesmo o planejamento estratégico, utilizados pelas empresas, desde a década de 60, como também pelos órgãos educacionais do governo, a exemplo do Plano Nacional de Educação (PNE), com suas mudanças pontuais com um olhar global em contraponto com o tradicional que tinha uma ampliação do passado com olhares limitados, consegue abarcar as necessidades da escola moderna. Não atende aos anseios de uma gestão escolar democrática, pois tem como característica observar os problemas externos para com isso retirar alguma vantagem.

Entendemos que no planejamento participativo em que há envolvimento de toda comunidade pautado e construído em cooperação, onde as tomadas de decisões são coletivas, e organizado tomando conhecimento da realidade e com flexibilidade permitindo sempre uma ação - reflexão - ação, é o planejamento utilizado por uma escola onde a gestão é democrática. 
No planejamento participativo o gestor não determina quais problemas e/ou ações são importantes, quais os objetivos, e quais metas serão determinadas para o trabalho durante o ano letivo, ele incentiva a participação de todos, amplia as discussões, colhe opiniões para a organização do cronograma, que será cumprido por todos.

Vasconcellos (2006) assim reporta sobre o ato de planejar:

E uma questão de respeito a si e ao grupo; ao não dedicarmos ao planejar, desvalorizamos nossa própria atividade. Também uma questão Ética, de responsabilidade por uma tarefa que assumimos e nos é delegada socialmente (VASCONCELLOS, 2006, p. 62)

A escola precisa deixar claro os objetivos, ou seja, onde, como, o que ela pretende alcançar após um tempo estabelecido. O bom planejamento participativo vai indicar as áreas de maior preocupação, quais as ações serão preponderantes para a construção da escola ideal daquela comunidade.

De acordo com o Portal Nova Escola ${ }^{1}$, outros motivos da evasão são a indisciplina e o desinteresse pelos estudos. Para uma parcela considerável dos jovens, a realidade exterior à escola é mais atrativa que a da sala de aula. Essa aparente indiferença tem a ver, na realidade, com baixa aprendizagem, atraso escolar, repetência e distorção idade-série ${ }^{2}$ (Vichessi e Nicolielo, 2014). O estudante desiste, pois não consegue entender o que a ele é transmitido em sala de aula. Desiste por não enxergar seus problemas sendo tratados no dia a dia. Não consegue aplicar o que a escola vê como importante na resolução dos problemas advindos da sua convivência em comunidade.

Acreditamos que, havendo um planejamento participativo tendo como foco maior a situação real e não a ideal, diminuirá consideravelmente a retenção e a distorção idade/série. As altas taxas de evasão e repetência são algumas das principais falhas do sistema educacional do país e o desconhecimento sobre os fatores que causam a repetência de tantos jovens no Brasil inibiu o desenvolvimento de políticas públicas eficientes (Gomes-Neto e Hanushek, 1994). A importância de melhor compreender a questão da repetência é a sua alta associação com a evasão escolar. Teremos então um ensino de qualidade.

De acordo com o Instituto Nacional de Estudos e Pesquisas Educacionais Anísio Teixeira (INEP), através do Censo da Educação Básica (BRASIL, 2019) a distorção idade-série em turmas comuns tem se tornado mais alta a partir do $3^{\circ}$ ano do EF e se evidencia até o $7^{\circ}$ ano dessa etapa e na $1^{\mathrm{a}}$ e $4^{\mathrm{a}}$ séries do EM. A taxa de distorção idade-série atinge $16,2 \%$ das matrículas no EF e $26,2 \%$ no EM. Além disso, o índice de distorção do sexo masculino é maior que o do sexo feminino em todas as etapas de ensino, de acordo com o gráfico abaixo.

\footnotetext{
${ }^{1}$ Nova Escola é uma marca da Associação Nova Escola, organização independente e sem fins lucrativos e é mantida pela Fundação Lemann. Além da revista, que tem mais de 30 anos de história, Nova Escola publica um site e possui perfis oficiais nas redes sociais.

${ }^{2}$ Expressa o percentual de alunos, em cada série/ano do Ensino Fundamental e Médio, com idade superior à recomendada.
} 


\section{Gráfico 1 - Distorção idade-série do Ensino Fundamental e do Médio segundo o sexo - Brasil} 2019

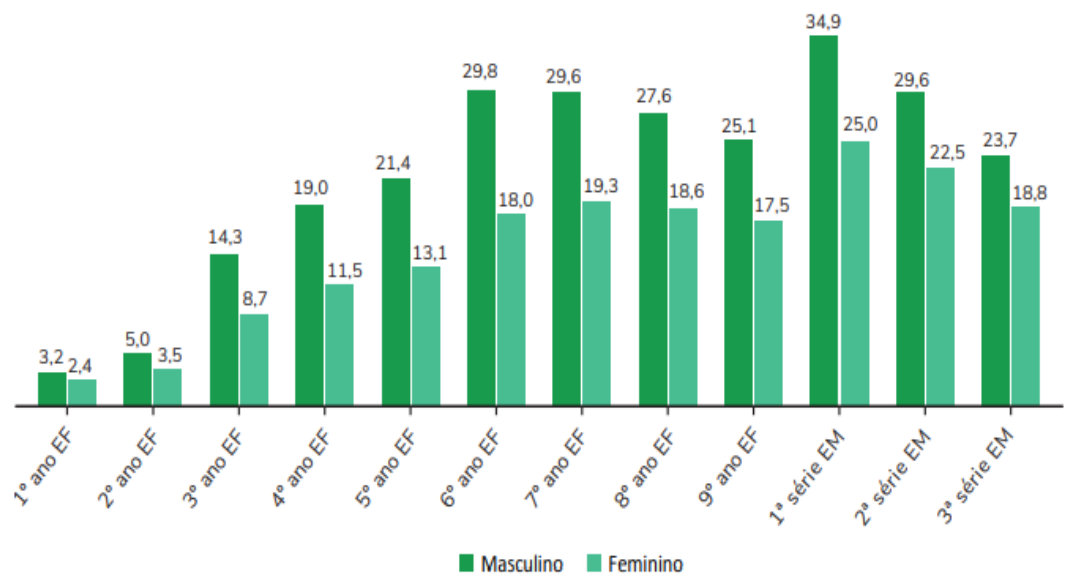

Fonte: Censo da Educação Básica 2019 - INEP/MEC (2019)

Segundo os dados do Censo Escolar 2019, a maior diferença entre os sexos é observada no $6^{\circ}$ ano do EF, no qual a taxa de distorção idade- série é de $29,8 \%$ para o sexo masculino e $18 \%$ para o sexo feminino

A forma de planejar, tendo um olhar criterioso sobre os indivíduos, seus medos, suas necessidades, suas dificuldades, criará um ambiente de troca de saberes onde cada ser será ouvido e poderá opinar sobre a forma de aprender e de entender o que ali será transmitido. Cada estudante fruto desse processo encontrará meios adequados de buscar soluções para seus problemas. Isso acontecendo, o planejamento cumpriu o seu papel, evitar aulas e propostas improvisadas, "presente" sem projeção para o futuro, análise de seus resultados de suas ações, promoção e definição de etapas dentre outros.

Nesse sentido o planejamento de cada escola deve ser único, pensado e planejado observando suas especificidades. A equipe gestora tem um papel importante neste processo, pois é ela que possibilita as chamadas para as discussões. Seus olhares deverão estar voltados para os sussurros, expressões faciais, falares, além das avaliações normatizadas, para entender se os objetivos propostos estão sendo atingidos ou não. Ao trabalhar a observação diária os envolvidos não precisarão esperar até um fim do prazo estabelecido para juntos inferirem. É por isso que o planejamento é flexível. Planejamento que faltou a educação brasileira em seu processo histórico. Esta seguia os planos dos mandatários, dos donos do poder. Ela não estava a serviço do povo, mas dos filhos dos poderosos, futuros donos do poder. A ela não necessitava compreender as demandas das classes menos favorecidas, ela servia a classe dominante. Os ideais, as ideias, o que ensinava e para quem ensinava respondia as perguntas feitas por esta classe. Em suma, percebemos, dentro do processo histórico de institucionalização da escola pública, que ela sempre foi vista como instrumento para manutenção da dominação, partindo da afirmação de Frigotto (1996, p. 44), que "a escola é uma instituição social que mediante suas práticas no campo do conhecimento, valores, atitudes e mesmo por sua desqualificação, articula determinados interesses e desarticula outros".

Reportando ainda ao Manifesto de 32, Anísio Teixeira lutou por uma escola gratuita, laica e produtora de conhecimento para todos os brasileiros. Ia de encontro com ideais vigentes. 
Acreditava que só através da educação haveria a democratização do Brasil. Educação da classe menos favorecida, visando o desenvolvimento de habilidades até então desconhecidas. Vejamos o que diz o Manifesto:

Em 1932, assinou o Manifesto dos Pioneiros da Educação Nova - manifesto redigido por Fernando de Azevedo, que preconizava a educação pública, universal, gratuita e laica; pública porque seria administrada pelo Estado; universal, significava a mesma educação básica para todos; gratuita, porque só assim, todos teriam acesso ao mesmo tipo de educação; laica, sem a ingerência da igreja ou religião (BRASIL, 1944).

Sabemos que a primeira forma de educação no Brasil foi a transmitida pelos Jesuítas, que pautavam seus ensinamentos nas crenças da Igreja Católica. Só em 1934, data da nova Constituição (1988) é que encontramos no seu artigo 149 que:

Art 149 - A educação é direito de todos e deve ser ministrada, pela família e pelos Poderes Públicos, cumprindo a estes proporcioná-la a brasileiros e a estrangeiros domiciliados no País, de modo que possibilite eficientes fatores da vida moral e econômica da Nação, e desenvolva num espírito brasileiro a consciência da solidariedade humana (BRASIL, 1988).

Hoje no Brasil, as políticas públicas que tratam da educação são legitimadas, além da Constituição Federal, a Lei de Diretrizes e Bases da Educação (LDB), sancionada pelo então presidente da República, Fernando Henrique, em 12/12/96, estabelece normas e procedimentos para todos os níveis da educação. Os Parâmetros Curriculares Nacionais (PCNs) que apontam metas capazes de ajudar no enfrentamento dos problemas advindos do mundo atual e o Plano Nacional de Educação (PNE, 2011) que estabelece diretrizes e metas para a educação.

Art. 2o São diretrizes do PNE - 2011/2020:

I - erradicação do analfabetismo;

II - universalização do atendimento escolar;

III - superação das desigualdades educacionais;

IV - melhoria da qualidade do ensino;

$\mathrm{V}$ - formação para o trabalho;

VI - promoção da sustentabilidade sócio-ambiental;

VII - promoção humanística, científica e tecnológica do País;

VIII - estabelecimento de meta de aplicação de recursos públicos em educação como proporção do produto interno bruto;

IX - valorização dos profissionais da educação; e

$\mathrm{X}$ - difusão dos princípios da equidade, do respeito à diversidade e a gestão democrática da educação (BRASIL, 2011).

Neste momento faz necessário uma reflexão sobre o pouco que aqui falamos. Oitenta anos desde que um grupo de pensadores imbuídos na luta por um Brasil mais justo já externava que só através da educação teríamos um país democrático. Somos conhecedores das leis que nos amparam enquanto educadores, mas nos preocupamos em conhecer as leis que amparam os estudantes em relação ao seu aprendizado? No Estatuto do Magistério ${ }^{3}$ (2002), no capítulo II art. $7^{\circ}$, vemos que,

\footnotetext{
${ }^{3}$ Lei no 8.261 de 29 de maio de 2002. Disponível em https://governo-ba.jusbrasil.com.br/legislacao/85404/lei-826102. Acesso em 22 de mar 2020.
} 
dentre outras atribuições do professor, ele deve "participar da elaboração da proposta pedagógica e do plano de desenvolvimento do estabelecimento de ensino". Como é difícil na maioria das escolas a construção do Projeto Político Pedagógico. Instrumento norteador das atividades que serão realizadas na instituição escolar. Se o professor não participa da construção do Projeto Político Pedagógico (PPP), como elaborará o Plano Anual, Plano de Unidade e de aula? Que metas ele deverá seguir? Para Vasconcellos, o PPP:

é um instrumento teórico-metodológico que visa ajudar a enfrentar os desafios do cotidiano da escola, só que de uma forma refletida, consciente, sistematizada, orgânica e, o que é essencial, participativa. É uma metodologia de trabalho que possibilita ressignificar a ação de todos os agentes da instituição (VASCONCELLOS, 1995, p.143).

O conceito apresentado tem como foco mostrar a importância, a funcionalidade e principalmente, a relação íntima que o mesmo possui com todos os agentes das unidades de ensino cuja participação na elaboração do PPP e efetivação do mesmo é de elementar importância e, de acordo com Fusari (2008, p. 45), "apesar de os educadores em geral utilizarem, no cotidiano do trabalho, os termos "planejamento" e "plano" como sinônimos, estes não o são."

Entendemos que somos frutos de uma escola tradicional, mas o Terceiro Milênio é regido pelos avanços tecnológicos. Um mundo onde a produção de informação é desumana, mas mesmo assim conseguimos no dia a dia conviver de forma pacifica com esta realidade. Mas na escola não conseguimos. Temos estudantes nativos da era digital e ainda planejamos aulas apostiladas, enquadradas engessadas e reclamamos por que os estudantes não prestam atenção.

Werneck (2012. p.70) assim contribui:

O professor precisa ter dois comportamentos básicos: investigar as diferenças individuais e, depois, avaliá-las em função da investigação feita. A dose de humildade deve ser muito grande porque o sistema está plantado sobre bases em que o professor, em cada disciplina, deseja que os alunos atinjam o máximo de desempenho em cada uma delas. O positivismo, através dos tempos, deixou-nos marcados por tantas regrinhas de convivência, e uma delas é esta mania que temos de trabalhar desconectados, como compartimentos fechados que se bastassem a si mesmos (WERNECK, 2012).

Num momento em que vivenciamos problemas referentes às atividades complementares (ACs), observamos quanto à falta de planejamento deixa a equipe gestora de fora dos problemas existentes em sala de aula no que tange a aprendizagem, pois estas dificuldades só se apresentam tardiamente ao final da unidade, quando poderia ser conhecido nas discussões geradas durante as ACs, no percurso da aprendizagem.

Se a escola possibilita ao educador ter suas ACs organizadas em horas seguidas e a equipe gestora se faz presente neste momento, conhecendo as dificuldades do dia a dia do educador, as dificuldades na aprendizagem dos discentes, as propostas apresentadas e corroborados pelo PPP, não temos dúvida, esta escola conseguirá trilhar um caminho em busca da democracia efetiva. 


\title{
ALGUNS FATOS DE ENSINO E APRENDIZAGEM
}

Estudantes em fase de alfabetização são sujeitos que, apesar de desconhecerem o sistema da língua escrita, formulam uma série de conjecturas sobre a modalidade que está aprendendo, baseando-se nas experiências de falante nativo. Muito mais do que expor a oposição entre os conceitos de alfabetização e letramento, Soares (1998) valoriza o impacto qualitativo que este conjunto de práticas sociais representa para o sujeito. Quanto a esse aspecto, Ribeiro sinaliza que a

\begin{abstract}
Alfabetização é o processo pelo qual se adquire o domínio de um código e das habilidades de utilizá-lo para ler e escrever, ou seja: o domínio da tecnologia - do conjunto de técnicas - para exercer a arte e ciência da escrita. Ao exercício efetivo e competente da tecnologia da escrita denomina-se Letramento que implica habilidades várias, tais como: capacidade de ler ou escrever para atingir diferentes objetivos (RIBEIRO, 2003, p. 91).
\end{abstract}

Essas experiências variam de aluno para aluno e ficam mais visíveis numa sala de primeira série do ensino fundamental, por exemplo, pois nem todas as crianças passaram por uma pré-escola ou tiveram alguma instrução dada pelos pais.

De acordo com Cagliari,

Estar na escola é um fato que cria expectativas. Mas alguns alunos podem ter uma visão muito restrita do que os espera. Por isso, é necessário que o professor, no início do ano, converse com seus alunos para saber de suas experiências com relação ao trabalho escolar que terão pela frente. Mas é bom também perguntar aos alunos quais são seus anseios. $O$ que eles pretendem ler? $O$ que eles pretendem escrever? O que pretendem fazer no começo da alfabetização? O que eles pretendem fazer depois, quando já souberem ler e escrever fluentemente? $\mathrm{O}$ que pretendem fazer depois, quando saírem da escola já formados? (CAGLIARI, 1998, p. 107):

Muitas crianças podem estar bem "atrasadas", em relação às demais, e é necessário atentar para suas dificuldades compreendendo suas dúvidas, evitando, desta maneira, que o descompasso torne-se motivo de inferioridade, sinônimo de incapacidade para aprender e, sobretudo, transforme-se num incentivo à evasão escolar.

Um método de alfabetização deve levar em conta o processo de aprendizagem, deixando um espaço para que o aluno exponha suas ideias a respeito do que aprendeu. A aprendizagem é construída na interação de sujeitos cooperativos que por meio da prática comunicativa alcançam seus objetivos que no momento são em comum; trata-se de aprender a ler numa visão ampla que tem como foco a compreensão, produzindo assim, uma atividade intelectual.

O professor não deve ensinar repetindo um modelo até que se aprenda, mas, é necessário que ele conheça as dificuldades no processo de aprendizagem de seu aprendiz e a partir daí compartilhar suas dificuldades analisando-as e sugerindo soluções que facilitem esse processo. Essa prática é realizada na escola onde desenvolvo meu trabalho, tanto por mim quanto pelos colegas.

É preciso criar estratégias de leitura e escrita, adaptadas às diferentes situações, variando de acordo com o texto a ser lido e o plano de abordagem elaborada previamente pelo leitor, utilizandose de um amplo esquema para obter, avaliar, utilizar informações para construir um significado 
enquanto se lê. Porém as ações que envolvem o ato de ler no âmbito escolar não apresentam objetivos específicos para esse fim. O que observamos, na maioria das situações, é um contexto em que "a atividade de leitura é difusa e confusa, muitas vezes se constituindo apenas em um pretexto para cópias, resumos, análise sintática, e outras tarefas do ensino da língua (KLEIMAN, 1999, p.30)".

As crianças não nascem sabendo usar as estratégias de leitura, muito menos as da escrita, entretanto, é preciso ensiná-las, com ênfase na capacidade de avaliação, controle e flexibilidade de ações que podem ser mudadas em decorrência das situações de leitura.

É importante ressaltar que as crianças não podem somente conhecê-las e sim saber usá-las mediante a variedade de textos. A relação professor-aluno nesse processo é de grande valia, pois o professor é que vai favorecer o estabelecimento do elo entre construção individual do aluno e as construções estabelecidas socialmente, sabendo que, a língua não se transmite. Os indivíduos não recebem a língua pronta para ser usada; eles mergulham na corrente de comunicação verbal e somente quando isto ocorre é que tomam consciência de si e do mundo que os cerca.

Nós professores devemos estar buscando possíveis meios para tentar melhorar o processo educacional brasileiro. Sabemos que o insucesso escolar ganha uma maior ênfase no que diz respeito á inabilidade dos alunos em ler e escrever. Então, nossa atuação está nessa área; por isso devemos planejar as atividades didáticas, com o objetivo de desencadear, apoiar e orientar o esforço de ação e reflexão do aluno.

\section{CONSIDERAÇÕES NADA FINAIS}

A ineficiência da prática pedagógica vem evidenciando-se no espaço escolar ao longo dos anos e muitas vezes é vista por muitos como um fator de desinteresse e ausência da família, entretanto os índices de evasão, reprovação e distorção idade x série $\mathrm{x}$ conhecimento tem provocado consequências desastrosas no âmbito da aprendizagem por parte dos envolvidos.

A distorção idade $\mathrm{x}$ série $\mathrm{x}$ conhecimento vem causando grande dificuldade para $\mathrm{o}$ desenvolvimento do processo ensino e aprendizagem, onde a baixa estima e baixa interatividade são vivenciadas constantemente no âmbito escolar. Portanto, sendo a escola um dos ambientes formadores de cidadãos críticos que constroem conhecimento mediante o processo ensinoaprendizagem é importante pensarmos sobre os modos de interação ali estabelecidos, a fim de compreendermos os fatores internos e externos que contribuem para a ineficiência da prática pedagógica em sala de aula.

A escola não deve ser a imagem e semelhança de seus educadores, mas de todos os segmentos que a compõem. Poder vislumbrar melhores condições de vida por atuarem como cidadãos exercitando sempre a sua cidadania. É uma situação política delicada se deixarmos que as mudanças ocorram de dentro para fora, porém se o embrião for gerado dentro da escola a transformação será lenta e bastante proveitosa para a qualificação de todos os envolvidos.

\section{REFERÊNCIAS}

BRASIL, Plano Nacional de Educação: Lei no 10.172/2001. Disponível em: $<$ portal.mec.gov.br $/$ índex.php?option $=$ com_content\&view $=$ article\&id $=16478 \& I t e m i d=11077$ ao $34 \mathrm{htm}>$.Acesso em: 20 fev. de 2019. 
Instituto Nacional de Estudos e Pesquisas Educacionais (Inep). CENSO DA EDUCAÇÃO BÁSICA | 2019 NOTAS ESTATÍSTICAS. Diretoria de Estatísticas Educacionais - DEED. Brasília: Inep, 2019. Disponivel em: http://portal.inep.gov.br/documents/186968/0/Notas+Estat\%C3\%ADsticas++ Censo $+d a+E d u c a \% C 3 \% A 7 \% C 3 \% A 30+B \% C 3 \% A 1$ sica $+2019 / 43 b f 4 c 5 b-b 478-4 c 5 d-a e 17-$

$7 d 55$ ced4c37d?version=1.0 Acesso em: Abri. de 2020.

- Constituição da Republica Federativa do Brasil: promulgada em 16 de julbo de 1934. Disponivel em: www.planalto.gov.br/ccivil03/constituicao/constitui\%C3\%A. Acesso em 08 fev. 2019.

, Leis de Diretrizes e Bases - LDB. Lei ñ 9.394. 1996. Disponivel em: Acesso em março de 2019.

INEP. "Manifesto dos Pioneiros da Escola Nova". Revista brasileira de estudos pedagógicos. - v. 1, n.

1 (jul. 1944). - Rio de Janeiro: Instituto Nacional de Estudos Pedagógicos, 1944 - Publicação oficial do Instituto Nacional de Estudos e Pesquisas Educacionais.

- Constituição (1988). Constituição da República Federativa do Brasil. Brasília, DF: Senado Federal: Centro Gráfico, 1988.

. Ministério da Educação. Secretaria de Educação Básica. Pradime: Programa de Apoio aos Dirigentes Municipais de Educaşão / Ministério da Educação. Secretaria de Educaşão Básica. Brasilia, DF: Ministério da Educação, 2006.176 p. (Caderno de Textos; v.1).

CAGLIARI. L. C. Alfabetizando sem o BA-BÉ-BI-BÓ-BU. São Paulo: Scipione, 1998. (Pensamento e ação no magistério).

FRIGOTTO, G. Educação e a crise do capitalismo real. 2. Ed. São Paulo: Cortez, 1996.

FUSARI, José Cerchi. O planejamento do trabalho pedagógico: algumas indagações e tentativas de respostas. Disponivel em: http:/ / www.crmariocovas.sp.gov.br/pdf/ideias_08_p044-053_c.pdf. Acesso em: 21 de mar 2020. GOMES-NETO, J. B. \& HANUSHEK E. A., (1994). Causes and Consequences of Grade Repetition: Evidence from Brazil. Economic Development and Cultural Change, v. 43, n. 1, p. 117-148.

KLEIMAN, A. Leitura: ensino e pesquisa. Campinas: Pontes, 1999.

MELLO, Guiomar Namo. Políticas públicas de educação. Estudos Avançados, vol 5. São Paulo. 1991. SCIELO.

QUEIROZ, Lucileide Domingos. Um Estudo Sobre a Evasão Escolar. UFPB. 2011.

RIBEIRO, V. M. (org.) Letramento no Brasil. São Paulo: Global, 2003.

SOARES, M. B. Letramento: um tema em três gêneros. Belo Horizonte, Autêntica, 1998.

VASCONCELLOS, Celso dos Santos. Avaliação: superação da lógica classificatória e excludente do "éproibido reprovar" ao é preciso garantir a aprendizagem. 15ªd. São Paulo: Libertad, 2006. . Planejamento: Plano de Ensino-aprendizagem e projeto educativo. São Paulo: Libertad, 1995.

PADILHA, R. P. Planejamento dialógico: como construir o projeto político-pedagógico da escola. São Paulo: Cortez; Instituto Paulo Freire, 2001.

WERNECK, Hamilton. Como ensinar bem e avaliar melhor. 10. Ed. Petrópolis: Vozes, 2012.

VICHESSI, B. Nicolielo, B. Periferias sem aulas e sem direitos. Nova Escola, 2014.

Submetido em abril de 2019

Aprovado em abril de 2020

\section{Informações do(a)(s) autor(a)(es)}

Nome do autor: Jucenilton Alves dos Santos

Doutorando em Educação - PPGE/UFSCar

Afiliação institucional: Secretaria Municipal de Educação e Cultura (SEMEC) de Itiruçu/BA. 
E-mail: jucenilton@gmail.com

ORCID: https://orcid.org/0000-0003-1446-4079

Link Lattes: http://lattes.cnpq.br/4923660984467727 